Synthesis, part of a Special Feature on Nudging Evolution? Critical Exploration of the Potential and Limitations of the Concept of Institutional Fit for the Study and Adaptive Management of Social-Ecological Systems

\title{
Fit in the Body: Matching Embodied Cognition with Social-Ecological Systems
}

Janne I. Hukkinen $^{l}$

ABSTRACT. Analysis of fit has focused on the macrolevel fit between social institutions and ecosystems, and bypassed the microlevel fit between individual cognition and its socio-material environment. I argue that the conceptualizations we develop about social-ecological systems and our position in them should be understood as ways for a fundamentally cognitive organism to adapt to particular social and ecological situations. Since at issue is our survival as a species, we need to better understand the structure and dynamics of fit between human cognition and its social-ecological environment. I suggest that the embodied cognition perspective opens up possibilities for "nudging" evolution through the conceptual integration of the cognitively attractive but ecologically unrealistic neoclassical economics, and the cognitively less attractive but ecologically more realistic adaptive cycle theory (panarchy). The result is a conceptually integrated model, the Roller Coaster Blend, which expresses in metaphorical terms why competitive individuals are better off cooperating than competing with each other in the face of absolute resource limits. The blend enables the reframing of messages about the limits of the social-ecological system in terms of growth rather than degrowth. This is cognitively appealing, as upward growth fires in our minds the neural connections of "more," "control", and "happy." The blend's potential for nudging behavior arises from its autopoietic characteristic: it can be both an account of the social-ecological system as an emergent structure that is capable of renewing itself, and a cognitive attractor of individuals whose recruitment reinforces the integrity of the social-ecological system.

Key Words: adaptive cycle; adaptive management; blending; cognitive anthropology; cognitive linguistics; conceptual integration; embodied cognition; environmental policy; neoclassical economics; panarchy; social-ecological systems; socioecological systems

\section{INTRODUCTION}

The concept of fit in the study of human-environmental interaction is usually understood as compatible matching between an institutional setting, associated ecosystem properties and properties of social-ecological relations. It is a normative notion, suggesting that an environmental governance system that is fit performs well over the long run and proves to be more resilient to shocks than a less structured system (Ostrom et al. 2007, Young 2008). Fit is ingrained in the study of human-environmental interaction: the journal Ecological Economics is "concerned with extending and integrating the study and management of 'nature's household' (ecology) and 'humankind's household' (economics)" (Ecological Economics 2012) and Folke and Gunderson (2002) "view[s] humanity and nature as co-evolving systems that interact within the bounds of the biosphere at various temporal and spatial scales and across scales".

An important aspect of fit has largely been missing from analytical focus. As biologically evolved cognitive organisms, any notion we develop of fit between institutions and ecosystems is underpinned by the evolutionary fit between our material environment and the abstract concepts with which we think. As researchers in the embodied cognition tradition point out, human cognition, including our most abstract thought, is grounded in and structured by the social and material reality in which it evolves and operates (Dennett 1991, Varela et al. 1991, Hutchins 1995, Lakoff and Johnson 1999, Feldman 2006, Slingerland 2008). A credible theory of fit between institutions and ecosystems can only be built on an understanding of how concepts articulating institutional rules are shaped by their social and material environment. Yet analysis of fit has focused only on the macrolevel fit between social institutions and ecosystems, and forgotten the microlevel fit between individual cognition and its sociomaterial environment. In this paper, I explore the implications of a focus on microlevel fit for the study and adaptive management of social-ecological systems (SESs).

Focusing on microlevel fit changes SES analysis radically from what it is in the case of macrolevel fit. In the study of macrolevel fit, the research question is whether or not the institutions fit the ecosystems. The empirical test is how well this fit is explained by a theory or model of SESs. In the study of microlevel fit, the research question is whether or not the SES theory or model fits our cognitive reality, or the way we think and feel. The empirical test is how well this fit is explained by a theory or model of cognition. Considering the microlevel fit introduces an additional criterion for assessing the goodness of a SES model: of all SES models that explain 
satisfactorily human-environmental interaction at the macrolevel, some are more satisfactory in a cognitive sense than others.

Here I probe the implications of microlevel fit by contrasting two theories, neoclassical economics (NCE) and adaptive cycle theory (ACT, a.k.a. panarchy). NCE is a theory which many scholars have criticized as being very poor in explaining the macrolevel fit of human-environmental interaction, because it fails to consider the broader ecological constraints of human economies (Daly 1990, Norgaard 1994, Boulding 1996, Jackson 2009). However, the microlevel fit of NCE would appear to be good, as evidenced by the electoral success of politicians sympathetic to viewing the global economy through the neoclassical lens. In contrast, ACT has attracted the attention of many SES researchers as an apt heuristic for understanding the macrolevel fit of human economies (Gunderson and Holling 2002, Holling 2004, Ostrom 2007, 2009). However, it is virtually unknown among the voters and decision makers of national and global economic systems, indicating poor microlevel fit. I ask: Is there an analytical way to improve the microlevel fit of ACT by integrating in it some of the cognitively fit components of NCE, without compromising the macrolevel fit of ACT?

The question is not just of theoretical interest. Despite mounting empirical evidence in support of humanenvironmental interaction models predicting serious predicament for humanity as a result of global environmental changes, this link between reality and models has failed to trigger significant change in resource allocation. In contrast, rapid and large-scale resource allocation followed when evidence of the global financial crisis of 2008 was linked with the NCE models of the global financial system (Petrella 2009). Obviously, the concentrated power structures of economic decision making enabled the resource allocation. But socially attractive mental models play a key role in the emergence and maintenance of all institutionalized power (North 1981, Lukes 2005), including that behind the recent financial decisions.

Focusing on the microlevel fit highlights the autopoietic and self-reflexive elements of human-environmental interaction. Autopoiesis refers to the characteristic of living systems to renew themselves and regulate this process in a way that maintains the integrity of their structure (Varela et al. 1974, Hofstadter 1979, Jantsch 1980, Maturana and Varela 1980, Maturana 2002, Polski 2009b). Margaret Polski summarizes the significance of autopoiesis for an individual: "Rather than strictly rational optimizers, we are complex, highly advanced sensors that adapt intuitively to particular physical and social contexts" (Polski 2009a:8). This has important implications for how human beings perceive themselves in relation to the SESs in which they operate. Conceptualizations about SESs and our position in them should be understood as ways for a fundamentally cognitive organism to adapt to particular social and ecological situations. At issue is adaptation, and therefore our survival as a species.

My aim in this paper is to show that the embodied cognition approach provides theoretical grounds for "nudging evolution," by which I mean the design of cognitively attractive and empirically sound mental models that have the capacity to alter people's behavior toward social-ecologically sustainable transitions (Thaler and Sunstein 2008:6, Farrell and Thiel unpublished manuscript). The approach facilitates the conceptual integration of two influential but contradictory traditions of thought on how human beings organize their economic activities with respect to each other and their resources-NCE and ACT. I pose the following research questions. First, what are the contours of a theoretical account of fit between human cognition and SESs (Methods)? Second, how does the theoretical account of fit advise us to reconceptualize urgent environmental challenges (Analysis)? Here I compare and integrate the heuristics of NCE and ACT. Third, is the resulting understanding of environmental challenges cognitively fit (Discussion)? Here I hypothesize how the analysis might inform the design of cognitively fit environmental policies. I conclude with a synthesis of the argument (Conclusion). Since the paper is an "experiment with theories," in which empirically grounded theories are reframed in metaphorical terms to tease out their cognitive significance, readers will notice along the way scientific terminology being transformed into metaphors of everyday life.

\section{METHODS: EMBODIED COGNITION AND FIT}

Embodied cognition builds on empirical research on the human brain and cognition, taking a critical stance toward the mind-body dichotomy that dominates much of Western philosophical tradition (Dennett 1991, Varela et al. 1991, Clark 1997, Lakoff and Johnson 1999, Slingerland 2008). According to this tradition, human beings have an autonomous faculty of reason that is seen as independent of perception and bodily movement. In contrast, embodied cognition takes "an evolutionary view, in which reason uses and grows out of such bodily capacities" (Lakoff and Johnson 1999:17). This position has important implications for theory building about culture and nature, because it means that even the most abstract concepts and categories of cultural production are embodied in our experience with nature. As Lakoff and Johnson (1999:20) put it, "an embodied concept is a neural structure that is actually part of, or makes use of, the sensorimotor system of our brains." This neglected point is where I begin my analysis. In environmental studies we seldom consider the conceptual systems with which we theorize about SESs as the products of our evolutionary fit with SESs.

In cognitive sciences, the embodied model of cognition is often contrasted with the computational model, which sees the human mind as an entity separate from its social and material environment. According to the computational model, 
informational input from the environment is transformed via sensory systems into symbolic representation (such as SES variables) on which computations are performed in the mind. Computational results are then transformed into output as human action upon the environment. In contrast, the embodied model sees the human mind as being constituted by the sociomaterial environment and extending functionally into that environment. Abstractions of the mind are not symbolic representations but rather neurally grounded in concrete sensorimotor experience (Clark 2011, Lakoff and Johnson 1999, Shapiro 2011).

Taking the embodied approach in this paper does not reflect any fundamental position on the tension between the embodied and computational view, which some cognitive scientists think should anyways be replaced with more integrative approaches (Clark 2011). However, embodiment opens up interesting integrative possibilities for tackling the long-running tension in environmental research between ecological and social phenomena. The embodied cognition approach bypasses the dichotomy between realism and constructivism (Gould 2000), invoking instead a conceptual blend between the two. Humans make sense of the reality around them with heuristic mental models that are based on universal, physiologically embodied capabilities. Yet these same embodied capabilities permit considerable variation in the heuristic claims that individuals make about truth, such that the claims may differ significantly depending on the social-ecological context within which they arise (Antal and Hukkinen 2010). It behooves us to understand the range of social-ecologically fit heuristics in a particular situation, while taking into account the embodied constraints of our cognition.

To succeed as an exercise tuned to the reality of embodied cognition, theories of human-environmental interaction must tackle the challenge of vertical integration. As Edward Slingerland (2008:9) puts it, "human-level structures of meaning need to be seen as grounded in the lower levels of meaning studied by the natural sciences, rather than hovering magically above them." Two mechanisms in particular achieve the vertical integration that Slingerland presumes: primary metaphor and conceptual blending.

Researchers of embodied cognition use the term primary metaphor to characterize their observation that the human mind connects subjective experience with sensorimotor activity. The primary metaphor is formed as a mapping from the source domain of sensorimotor activity to the target domain of subjective experience (Lakoff and Johnson 1980, 1999, Gentner 1983, Gentner et al. 2001). From the neural perspective, primary metaphors are the outcome of associative learning, which in turn is grounded in a basic fact about brain physiology: mental connections are active neural connections. As Jerome Feldman explains (2006:202), "when subjective and sensorimotor experiences are brought together in an episode, both domains are coactive. This, according to association learning theory, causes the strengthening of connections between the neural circuits supporting the different modalities. The new, strengthened connections physically constitute the metaphorical mapping." For example, in the primary metaphor Affection is warmth, the source domain's sensorimotor experience of temperature is projected onto the target domain's subjective experience of affection. It is easy to see how embodied experiences of the human animal evolution, such as being held in the arms of one's mother, would generate associative mappings such as these. Other key primary metaphors from the point of view of this paper are More is up, Control is up, and Happy is up (further examples are in Table 1, column 1) (Lakoff and Johnson 1999:50-54).

The primary metaphor offers the first criterion for assessing the microlevel fit between cognition and SESs. I call it cognitive appeal. A human-level structure of meaning, such as a SES theory or model, has cognitive appeal when it contains primary metaphors associated with positive subjective experiences, such as happiness, affection, and good.

Primary metaphors are the largely universal, neuron-based foundation of more complex language and thought (Lakoff and Johnson 1999:45-59 summarize primary metaphors empirically observed across cultures and languages). They constitute an objectively real, basic level evolutionary fit between cognition and SESs that few human beings can avoid, having been born as a member of our particular species on this particular planet (Slingerland 2008). What is more, they are the building blocks of an infinite number of more complex, socially constructed metaphors that provide the scaffolding for cultural evolution (D'Andrade 1995, Tomasello 1999). Cognitive linguists characterize the process by which the more complex metaphors are formed with the term conceptual integration, or conceptual blending (Fauconnier and Turner 1998, 2002).

Conceptual blending aligns partial domains of knowledge, such as primary metaphors, to form a separate domain of knowledge, called the blend. The blend does not simply add the partial domains of knowledge. It rather completes what are only barely distinguishable patterns in the partial domains of knowledge into a new domain of knowledge qualitatively different from the partial inputs. Blending is thus different from standard analogical reasoning, in which a source domain is mapped onto a target to make inferences easily available in the source (Fauconnier and Turner 2002). Blending is considered to be a basic cognitive operation performed at different levels of abstraction and under superficially divergent contexts (Fauconnier and Turner 1998). It enables the generation of new meanings and understandings through partial metaphorical combination of existing concepts (Feldman 2006). 
Table 1. Transformation of event structure metaphors into conceptual blends between neoclassical economics and adaptive cycle theory.

\begin{tabular}{|c|c|c|c|}
\hline $\begin{array}{l}\text { Component primary metaphor in } \\
\text { event structure metaphor }\end{array}$ & $\begin{array}{l}\text { Evidence of primary metaphor in } \\
\text { Neoclassical economics event } \\
\text { structure metaphor } \\
\text { ("I need to continuously maximize my } \\
\text { utility in competition with others. } \\
\text { Utility is money and power.") }\end{array}$ & $\begin{array}{l}\text { Evidence of primary metaphor in } \\
\text { Adaptive cycle event structure } \\
\text { metaphor } \\
\text { ("We need to sustain adaptive } \\
\text { capacity of social-ecological system. } \\
\text { Adaptive capacity is a cycle between } \\
\text { slow growth and rapid dissipation.") }\end{array}$ & $\begin{array}{l}\text { Conceptual blend between } \\
\text { Neoclassical economics and } \\
\text { Adaptive cycle theory } \\
\text { ("I need to sustain adaptive capacity } \\
\text { of social-ecological system in } \\
\text { cooperation with others.") }\end{array}$ \\
\hline
\end{tabular}

\begin{tabular}{ll}
\hline System is physical structure & -Utility is an uphill slope \\
& -Slope has no limits \\
& -Lonely riders compete with each \\
& other going uphill
\end{tabular}

States are locations (bounded regions in space)

Changes are movements (into or out of bounded regions)

Causes are forces

\begin{abstract}
Actions are self-propelled movements
\end{abstract}

Purposes are destinations

Means are paths (to destinations)
-Lonely rider with money and power remains on slope

-More/less money and power is moving uphill/downhill -Uphill movement continues forever, downhill movement is temporary -The slope does not erode from traveling on it

-Lonely rider's need to maximize money and power is the force that makes him move uphill

-Action is lonely rider moving uphill or preventing downhill movement

-Maintaining money and power is staying inside the vehicle -Lonely rider maximizes money and power by staying ahead of others in the uphill climb

-Maximizing money and power requires maintaining the vehicle

-To make money and gain power, the lonely rider moves on uphill path
-Social-ecological system is a roller coaster track

-Roller coaster track has limits defined by the cycle shape
-Slope becomes a cycle by linking downhill with uphill

-When join downhill with uphill, lonely riders become roller coaster riders riding the track together - Since roller coaster riders are linked on single track, they cannot compete as individuals and must cooperate

-Dynamics of adaptive social-

-Adaptive roller coaster riders remain ecological system follow the shape of together on roller coaster track roller coaster track

-Sometimes adaptive roller coaster riders have money and power

-Dissipation of potential is growth of $\cdot$ When wealth increases, resilience resilience and connectedness in $r$ turn diminishes (in conservation) or of track

-Growth of potential and connectedness is dissipation of resilience in $\mathrm{K}$ turn of track -Dissipation of potential and connectedness is growth of resilience in $\Omega$ turn of track connections diminish (in reorganization)

-When wealth diminishes, resilience increases (in release) or both resilience and connections increase (in exploitation) -Growth of potential and resilience is prevent track from deteriorating dissipation of connectedness in $\alpha$ turn of track

-More/less adaptive capacity is roller coaster track in good/poor shape

-The need for adaptive capacity is the force that maintains movement of

- Roller coaster riders coordinate money and power to maintain social-ecological system along roller movement along roller coaster track coaster track

-Action is quicker or slower motion of social-ecological system along roller coaster track

-Action is roller coaster riders moving at variable speed on roller coaster tracks

- Maintaining adaptive capacity is building and repairing roller coaster track

-Adaptive roller coaster riders maintain roller coaster and track -Adaptive riders all stay inside vehicle on roller coaster tracks -Adaptive riders experiment with safe limits of roller coaster speed -Adaptive riders change roller coasters at bottom station

-Adaptive capacity is a cycle of growth and dissipation -Growth requires dissipative turn on roller coaster track

-Dissipation requires turn toward growth on roller coaster track
-To achieve growth, riders move up and down on roller coaster tracks

-To achieve growth in one dimension, riders must accept reductions in other dimensions 
Expected progress is travel schedule (schedule is reaching prearranged destination at prearranged time)

Difficulties are impediments to motion

External events are large moving objects.

-Recession is getting hit by landslide

-The lonely rider's life is speeding

Long-term purposeful activities are journeys
-Lonely rider advances his career by achieving next post on path up as quickly as possible

- Recession means uncontrolled slide downhill

-Losing competition is being left behind in the climb

-Not making ends meet is moving more downhill than uphill

- Regulation is rough terrain

-Regulation is heavy burden
-Advancing adaptive capacity is having optimal speed going up and down

-Losing adaptive capacity is letting roller coaster track deteriorate -Regulation prevents experimentation with safe roller coaster track design
- Roller coaster riders advance their personal careers by collaborating to maintain optimal speed going up and down

-Recession means gaining downhill speed to be able to go uphill (neoclassical economic difficulties are adaptive cycle means) -Losing competition is waiting for right moment to climb up (difficulties $=$ means) -Losing competition is having a rough ride -Losing adaptive capacity is a stalled roller coaster -Regulation prevents experimentation with safe roller coaster track design and riding speed

-Catastrophe is collapsing roller coaster

-Breakdown of social-ecological
system is collapsing roller coaster

-Social-ecological life is a roller coaster track that offers a pleasant ride
-Personal life is a pleasant roller coaster ride with others
A well-known example of a conceptual blend is the inferential solution to the riddle of the Buddhist monk (Appendix 1). The monk begins walking up a mountain at dawn, reaches the top at sunset, meditates there for several days, and one dawn begins to walk back to the foot of the mountain to reach it at sunset. The task is to prove that there is a place on the path which he occupies at the same time of day on the two journeys. The inferential solution is to imagine the monk walking both up (input 1 of the blend) and down (input 2 of the blend) the path on the same day. There must be a place where he "meets himself" on the path (the blend) and that place is the one he would occupy at the same time on the two journeys (Fauconnier and Turner 1998:136-141).

The blend has an emergent structure that is not copied form the input spaces. This is achieved through composition, completion and elaboration. Blending composes elements from the input spaces and provides relations that do not exist in the input spaces, such as the two monks making two journeys. Blending completes the composed structure by recruiting a considerable amount of background conceptual structure and knowledge. The monk riddle is completed by recruiting the familiar scenario of two people encountering each other on a path. Finally, the blend is elaborated by "running the blend", that is, through imaginative mental simulation that follows the principles and logic of the blend: having encountered each other, the imaginary two monks might begin a conversation (Fauconnier and Turner 1998, Feldman 2006). Running the blend in terms of uphill and downhill movement is an important feature of my comparative analysis of the dynamics of NCE and ACT, because it achieves conceptual integration of the human-environmental interaction heuristics underlying the two theories.

Although a large number of different conceptual blends can be constructed from the input spaces, some blends are better than others. This provides the second criterion for assessing the microlevel fit, namely, cognitive optimality. The optimality principles of blending are integration, topology, web, unpacking and good reason (Fauconnier and Turner 1998:162-3). The blend is integrated when it provides a tightly integrated scene that can be manipulated as a unit (such as the blend in the monk riddle). The blend has topology when the relations of an element observed in the blend match those of its counterpart in an input space. The blend is an integrated web when manipulating the blend as a unit maintains its connections to the input spaces without surveillance or computation. Unpacking is possible to perform on the blend when it is transparent enough for an observer to reconstruct the mappings and connections between the blend and its input spaces. Finally, there is good reason for each element of the blend to be there, including relevant links to other mental spaces and relevant functions in running the blend (Appendix 1 and Figure A1.1).

\section{ANALYSIS: COGNITIVE FIT OF NEOCLASSICAL ECONOMICS AND ADAPTIVE CYCLE THEORY}

To work out the environmental policy relevance of fit between individual cognition and SESs, I construct a blend that aims to overcome a predominant contradiction in human- 
environmental interaction: the independence from ecosystem services that individuals perceive they possess as a result of technological and economic development, and the highly coupled dependence on these services that such development in fact creates for individuals. As Antal and Hukkinen (2010) illustrate, the contradiction has been observed in different variations in numerous well-known syntheses of humanenvironmental interaction (Bateson 1972, Smil 1993, Bennett 1996, Redman 1999, McNeill 2000, Diamond 2005).

In theoretical terms, the contradiction can be nicely summarized as one between NCE, which informs an individual's perception of independence from ecosystems, and ACT, which explains the individual's dependence on ecosystems. NCE takes the individual perspective and considers society to be made of selfish individuals striving to maximize their personal utility while interacting with other individuals in free markets that rely on free ecosystem services (Smith 1937, Boulding 1955, Peterson 1973). ACT takes the systemic perspective and considers society to be made of social and ecological systems interacting with each other and with other SESs at lower and higher system levels (Gunderson and Holling 2002, Holling 2004, Ostrom 2007, 2009). The contradiction is between what individuals belonging to a SES perceive the reality to be and what the reality of the SES is. Individuals follow the market rules built on NCE and behave as if the technological and economic development enabled by the markets would make them ever more independent of ecosystems. But in reality, as ACT explains, the same development is tightly coupled with the natural resource base and renders every individual ever more dependent on ecosystems. I search for a resolution to the contradiction by constructing a conceptual blend between the two competing models. The resolution speaks directly to contemporary environmental policy, since major and urgent behavioral change is required to address the unprecedented environmental challenges facing humanity (Ehrlich and Kennedy 2005, Rockström et al. 2009, Antal and Hukkinen 2010).

It is important to recruit NCE in the effort to reconceptualize human environmental challenges, because it is cognitively more appealing and optimal than ACT. To see why this is so, let us investigate visualizations of the two models. Advertisements espousing the virtues of the neoclassical economy typically have concrete things moving along an endless uphill to depict unlimited growth. My collection of business school ads published in The Economist in 2010-11 has joggers, rock climbers, juggler's balls, birds, pencils, Earth, airplane and bicycle rider moving up. According to the theory of primary metaphors this is cognitively appealing, because More is up, Control is up, and Happy is up. Contrast this with the metaphorically poor visualization of the ACT, which strives to explain the dynamic transformations taking place in a complex SES in terms of three abstract dimensions: potential, connectivity and resilience. The visualization of NCE is also cognitively more optimal than that of ACT. The business school ads depict integrated scenes made of familiar elements that all have good reason to be in the ad, and it is easy to "run" each scene as an uphill movement of one thing or another. The ACT model is integrated as well, but running it as a mental simulation is much more difficult, because it is not immediately clear whether there is a thing doing something in the model and if so, what the thing might be.

It is therefore worthwhile to untangle and exploit the cognitively appealing and optimal elements of NCE. Building on and with dominant intellectual commitments such as NCE makes use of the so-called ratchet effect, or the process by which cultures have been found to evolve through periodic modification of cultural practices adopted from earlier generations (Tomasello 1999). This does not, however, imply incremental transitions. As was pointed out in the Methods section and will be illustrated shortly, conceptual blending holds potential for radical reconceptualization and reframing. Radical change in incremental steps is also consistent with contemporary theorizations of social-ecological transitions, which argue that a SES can be heading in a new direction with new attractors of radical systemic change, albeit in small steps (Fischer-Kowalski and Rotmans 2009).

The analysis proceeds as a decomposition of the views of NCE and ACT on human-environmental interaction into their component primary metaphors, and a recomposition of the primary metaphors into a new conceptual blend of humanenvironmental interaction. First, I present the respective positions of NCE and ACT on human-environmental interaction in concise statements of natural language. Second, I identify the event structure metaphors underlying the natural language statements. Event structure metaphors are conceptual blends of motion-based primary metaphors used to describe complex events, in this case the dynamics of the market economy or of a SES (Lakoff and Johnson 1999, Feldman 2006). Third, I recompose a novel conceptual blend, the Roller Coaster Blend, from the primary metaphors of NCE and ACT. The guiding principle in recomposing the blend is to maximize its cognitive appeal and optimality while maintaining its ecological soundness.

\section{Neoclassical economics and adaptive cycle theory in natural language}

Adam Smith summarizes the individualistic essence of the NCE view of society in The Wealth of Nations (Smith 1937:423):

By preferring the support of domestic to that of foreign industry, [the individual] intends only his own security; and by directing that industry in such a manner as its produce may be of the greatest value, he intends only his own gain, and he is in this, as in many other cases, led by an invisible hand to 
promote an end which was no part of his intention. [...] By pursuing his own interest he frequently promotes that of the society more effectually than when he really intends to promote it.

Smith's point-particularly its later interpretation-is of "fundamental significance" for contemporary neoclassical theory: "Competition must be present if a market system built upon the pursuit of self-interest is to maximize simultaneously both individual and social interest" (Peterson 1973:46-47). The maximization has no limits in the neoclassical view. If full employment of existing capital and contracted labor is to be sustained, investment and output in the economy-in other words, both the potential for output and the output itselfmust increase from year to year in the long run, despite shortterm cyclic economic downturns (Boulding 1955, Peterson 1973) (Figure 1).

Fig. 1. Long-term economic growth with short-term downturns (adapted from Boulding 1955:451, Fig. 65B).

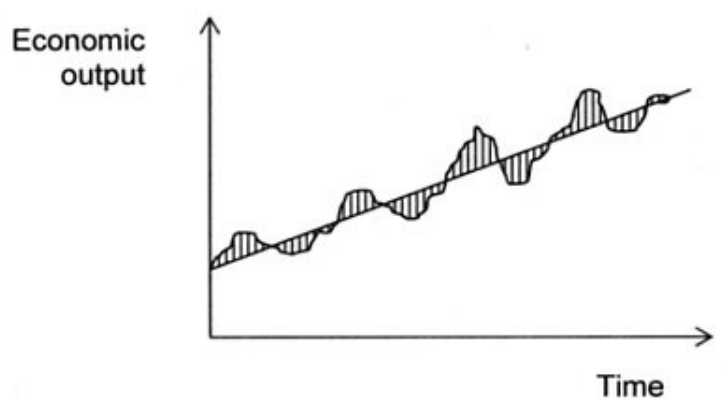

Contrast the NCE view with that of ACT. ACT is an attempt to understand the structure and dynamics of complex SESs at different levels of observation. Three properties are seen to shape the dynamics of change in the cycle: potential, which refers to the system's accumulated economic, ecological and social resources and measures its potential for change; connectedness, which refers to interdependencies among the internal variables and processes, and measures their sensitivity to external variation; and resilience, which refers to the system's ability to return to its preceding state after a disturbance, and measures its vulnerability to unexpected or unpredictable shocks. The three properties constitute a threedimensional space within which the SES undergoes cyclic adaptive changes from exploitation phase (r) to conservation phase $(\mathrm{K})$ to release phase $(\Omega)$ to reorganization phase $(\alpha)$, and then back to $\mathrm{r}$ (Gunderson and Holling 2002) (Figure 2). Originally developed from empirical studies on ecosystem dynamics (Holling 1973), ACT has since been applied as a heuristic to understand the dynamics of change in broader SESs (Holling and Gunderson 2002, Holling 2004).
Fig. 2. The adaptive cycle. $r=$ exploitation phase, $\mathrm{K}=$ conservation phase, $\Omega=$ release phase, $\alpha=$ reorganization phase (Gunderson and Holling 2002).

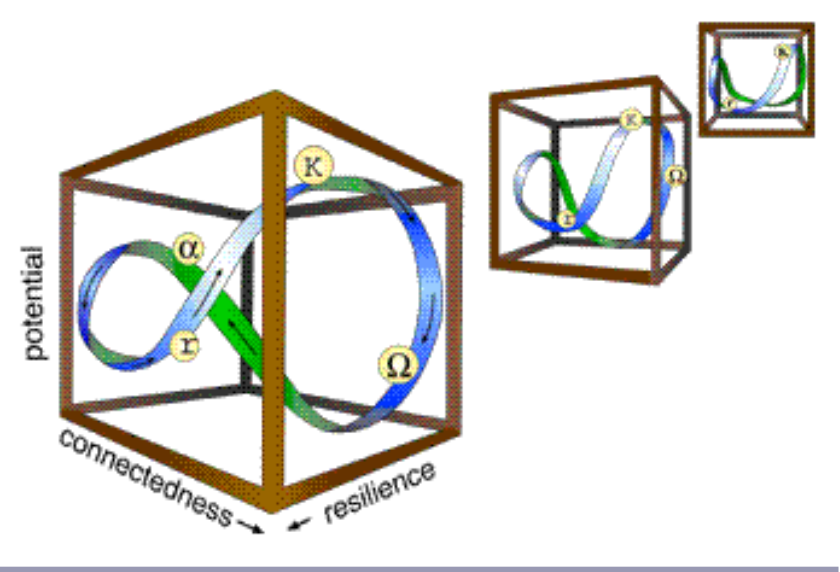

The adaptive cycle has both similarities and differences with the neoclassical perspective. Both approaches contain the notion of output potential, measured in terms of accumulated resources, and in both approaches this potential is understood to be growing and contracting. In NCE, however, the longterm trend is one of endless growth in output potential, whereas in ACT the long-term trend is cyclic change in output potential during exploitation, conservation, release and reorganization, constrained by the limits and dynamics of related adaptive cycles in SESs at lower and higher system levels (Gunderson and Holling 2002, Holling 2004). Another difference is that the growth and contraction cycles in NCE relate to output potential alone, whereas in adaptive cycle also connectedness and resilience grow and contract cyclically. This means that there are synergies and tradeoffs in the growth and contraction of a SES (Figure 2). Last but not least, the neoclassical approach emphasizes the importance of selfish individuals for optimal functioning of the economic system. The adaptive cycle approach is less clear on the matter. Some authors in the field tend more in the individualistic direction (Holling 1978, Brock et al. 2002), whereas others lean toward collective design of social institutions to achieve appropriate governance of the SES (Westley 2002, Westley et al. 2002).

The methodology presented in this paper suggests an emergent model positioned between individualistic and collective explanations. The blend between the cognitively fit NCE and the ecologically fit ACT sketches a hypothetical model of autopoiesis, whose adoption by individuals maintains the process of autopoiesis. On one hand, the blend aims to explain the interaction between individual and collective levels in a SES as an emergent structure that renews itself; on the other hand, the blend aims to maintain the integrity of the SES by 
doing the explaining in a way that individuals belonging to the SES find attractive. Were the model true, there would be a feedforward from individual to collective level when more and more individuals embrace cognitively appealing and optimal SES models which then become stabilized as socially shared thought and action, and a feedback from collective to individual level when more and more institutions are designed on the foundation of the stabilized models and begin influencing individual behavior (North 2005, Sawyer 2005).

\section{Decomposition of event structure metaphors}

We are now in a position to identify the event structure metaphors underlying these natural language descriptions of $\mathrm{NCE}$ and ACT. I will first present the generic structure of the two respective event structure metaphors in terms of their component primary metaphors (Table 1, column 1) and thereafter show evidence of the existence of the event structure metaphor in both the NCE perspective (Table 1, column 2) and the ACT perspective (Table 1, column 3). At this stage of the analysis, readers will observe how theoretical terminology is transformed into metaphorical language. This is an unconventional but necessary analytical step, because it enables me to build the argument on what is known about the embodiment of human cognition.

An event structure metaphor relies on the common frame of motion or journeys, including concepts such as locations, movements, paths and forced movements. We know from empirical cognitive research that human beings tend to compress their understanding of an event into an event structure metaphor, which combines several primary metaphors into a more complex structure. The event structure metaphor has been found in every language that has been empirically studied, and language users have been found to apply it in a wide range of contexts (Lakoff and Johnson 1999, Feldman 2006).

The event structure metaphor produces a general mapping between physical journeys and any goal-oriented activity, however abstract. In a generic event structure metaphor, whose component primary metaphors are listed in column 1 of Table 1 , the system under consideration is thought of as a physical structure and system states are physical locations. System changes are conceived of as movements of the elements that make up the system and the causes of system changes are forces upon the elements. Actions are self-propelled movements; the purposes of actions are destinations; the means of actions are paths to destinations; and expected progress in the actions taken is a travel schedule. Difficulties are impediments to moving along the path and external events are large moving objects. Overall, long-term purposeful activity within a system is considered a journey (Lakoff and Johnson 1999, Feldman 2006).

Let us go through the System is a physical structure primary metaphor in the event structure metaphor (Table 1, column 1) to see how the primary metaphors of NCE (Table 1, column 2) and ACT (Table 1, column 3) differ from each other. Appendix 2 contains a detailed explanation of the rest of the decomposed primary metaphors in Table 1.

System is a physical structure.

To be very concrete, I have condensed the physical system of NCE into a visual image (Figure 3, Input space 1). It originates in the upward curve with which long-term economic growth is depicted in NCE (Figure 1). The image also includes a competitive individual racing uphill in a vehicle, which is the stereotypical way to depict growth. The image in Input space 1 of Figure 3 reminds us of the Buddhist monk riddle, as it has individuals racing uphill in vehicles, reflecting their competitive pursuit to maximize self-interest with the help of technology. Despite occasional downhill slides during economic downturns, the overall progression is upward on the slope. Unlike the monk riddle, there is no end to the slope, as the economy continuously grows. These component primary metaphors are presented in Table 1, column 2.

Fig. 3. Conceptual blending of neoclassical economics and adaptive cycle theory. $\mathrm{T}=$ time, $\mathrm{P}=$ potential, $\mathrm{C}=$ connectedness, $\mathrm{R}=$ resilience.

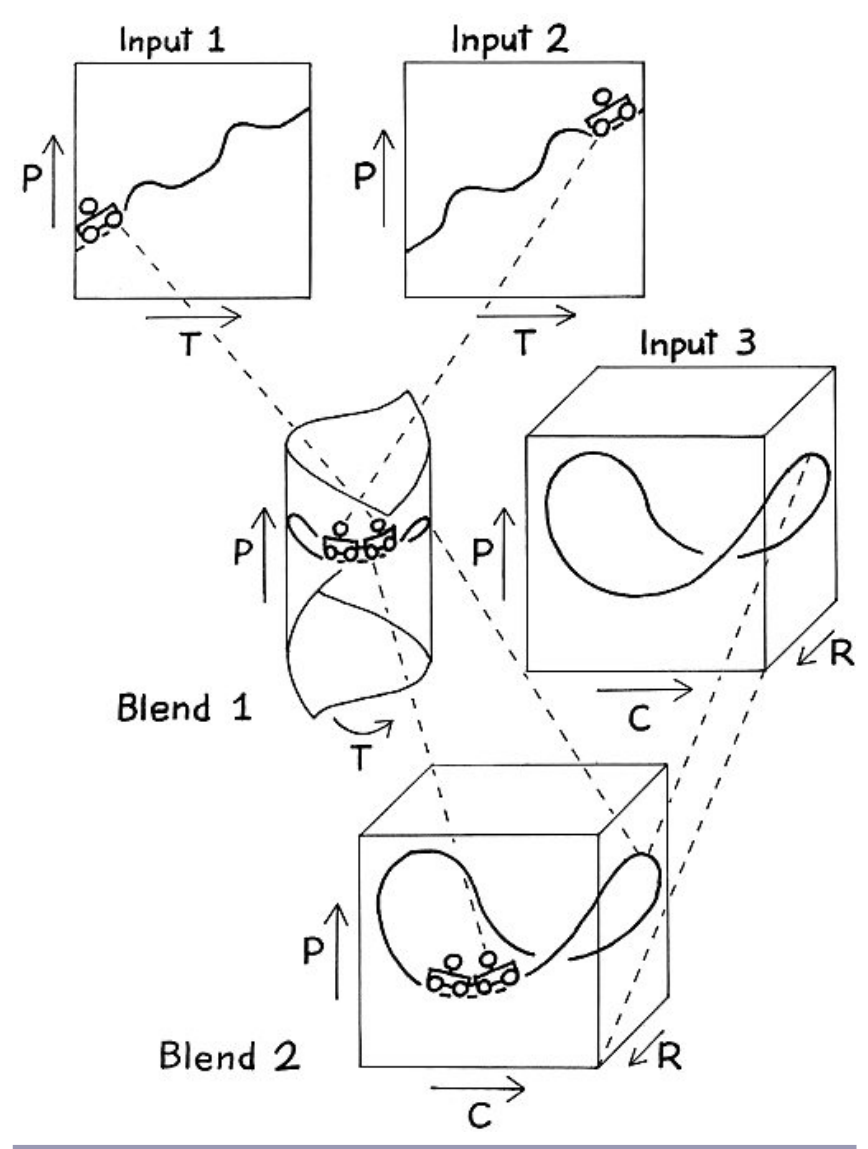


Now compare the physical structure of NCE with that of ACT. The adaptive cycle can also be condensed into a visual image, namely, a roller coaster track (Figure 3, Input 3). This image, too, originates in the curve with which the adaptive cycle is depicted in scientific literature (Figure 2). Unlike in the neoclassical image, the path does not progress continuously upward but rather goes up and down within the limits of a roller coaster track known as an Out and Back Roller Coaster in the literature devoted to the topic (Roller Coaster DataBase 2010). The component primary metaphors are in Table 1, column 3.

The images in Figure 3 compress complex event structure metaphors describing social-ecological dynamics into relatively simple images. Images are one way to present an event structure metaphor in condensed form (Turner and Fauconnier 1999), but there are other ways, such as the verbal descriptions of the images I have given above and in Table 1. Undoubtedly, many other possible images come to mind as equally good visualizations. In choosing these particular images I have purposefully looked for what cognitive anthropologists and cognitive linguists call basic level categories, that is, categories that optimally fit our bodily experiences of entities (Rosch 1973, D'Andrade 1995, Lakoff and Johnson 1999, Feldman 2006). Basic level categories are in the middle of hierarchies of categories. In the neoclassical image (Figure 3, Input 1), for example, I introduce a slope, which is in the middle of the hierarchy topographical difference-slope-Double Black Diamond. In the adaptive cycle image (Figure 3, Input 3), the roller coaster is in the middle of the hierarchy amusement park equipment-roller coaster-Wild Mouse roller coaster. Most people have little trouble associating familiar mental images and sensorimotor programs for interacting with a mountain slope or a roller coaster. But the familiarity disappears both with the superordinate categories of topographical difference and amusement park equipment, and with the subordinate categories of Double Black Diamond slope and Wild Mouse roller coaster.

\section{Conceptual blending of primary metaphors}

The component primary metaphors identified in Table 1 are the building blocks of a conceptual blend between NCE and ACT. As before, it is helpful to begin the analysis with an image. The overall process of constructing the conceptual blend from the respective event structure metaphors of NCE and ACT is illustrated in Figure 3. The blending takes place in two stages. In the first stage, the two input spaces of the intermediate blend (Blend 1 in Figure 3) are a lonely rider moving uphill in a vehicle in the lower part of the metaphorical slope of NCE (Input 1) and a lonely rider moving uphill in the upper part of the slope (Input 2). Blend 1 can be visualized as an imaginary folding of a 2-dimensional plane into a 3dimensional cylinder. In the second stage, the two input spaces are the intermediate blend of the first stage (Blend 1) and the metaphorical roller coaster track of the adaptive cycle (Input 3 ). The conceptual blend (Blend 2) - the Roller Coaster Blend -is summarized verbally in column 4 of Table 1 . Below I explain in detail the blended primary metaphor System is a physical structure. The rest of the blended primary metaphors are explained in Appendix 2.

System is a physical structure.

The key embodied observation in constructing this conceptual blend between NCE and ACT is that a slope becomes a cycle by linking the downhill with the uphill. When the neoclassical economy's downhill is linked with its uphill, the two lonely riders become a roller coaster train riding on the same track together. Instead of a continuous uphill climb, change in the new system is one of alternating uphill and downhill movement on a circular track. In the Roller Coaster Blend, riders who are linked together and riding on the same track cannot compete as individuals and must therefore cooperate (Figure 3 and Table 1, column 4). The experience is known even to today's market entrepreneurs, who merge, co-opt, connect with government, enter joint ventures and cooperate in many other ways (Scott 1987). While some of this cooperation is motivated by economies of scale, monopolies and higher rates of capital accumulation, there is also evidence of enterprise cooperation motivated by social responsibility, when strong regulations, pressure from nongovernmental organizations, institutionalized stakeholder dialogue and encouraging social norms are present (Campbell 2007). Under conditions of diminishing natural resources and ecosystem services, cognitively appealing mental models can facilitate the emergence of such cooperative cultures and institutions.

The new Roller Coaster Blend implies dynamics that are woven in the fabric of the economic system itself. Joseph Schumpeter called it "the process of Creative Destruction" that "incessantly revolutionizes the economic structure from within, incessantly destroying the old one, incessantly creating a new one" (Schumpeter 1976:73). The promise of the blend is that the destruction of wealth, connections and resilience during the release stage (Figure 2, see also Appendix 2) is a prerequisite for long-term creation of new social organization that deploys new technology based on a different resource (Schumpeter 1976). In the adaptive cycle literature such creative destruction has been visualized as a collapse that takes place in the adaptive cycle at one level and interacts with adaptive cycles at higher and lower level panarchies (Gunderson and Holling 2002). In the Roller Coaster Blend, the creative destruction can be visualized as a change in the shape of the track.

In sum, the novel physical structure of the conceptual blend animates the roller coaster track of the SES with real human beings and visualizes a situation in which the winners and losers of the neoclassical competition cooperate with each other. It also explains functionally the absolute limits of the 
SES. Kenneth Boulding's well-known metaphors find their place in the Roller Coaster Blend: the lonely, reckless and exploitative cowboys of the limitless neoclassical race are reined in by the folding of the linear track into a spaceship roller coaster, in which the riders adjust themselves to a cyclical ecological system with continuous material reproduction (Boulding 1996).

\section{DISCUSSION}

The Roller Coaster Blend fulfills the cognitive optimality principles. It is integrated in the sense that the Out and Back roller coaster track with riders in a train of vehicles running along the track is a tightly integrated scene that can be manipulated as a unit. The blend has topology in the sense that the relations of an element observed in the blend match those of its counterpart in an input space: gaining/losing potential is going uphill/downhill on the blend's roller coaster track, but the same relation holds also in the uphill/downhill movement of the rider in the neoclassical input space and in the maxima/ minima of the function depicted in the adaptive cycle input space; and the relation between the roller coaster vehicle and the track in the blend matches the relation between the lonely rider's vehicle and the uphill slope in the neoclassical input space (Figure 3). The blend is an integrated web in the sense that manipulating the blend as a unit maintains its connections to the input spaces without surveillance or computation, as illustrated for example by the numerous manipulations of the blend in column 4 of Table 1. Unpacking is possible to perform on the blend, in other words, the blend is transparent enough for an observer to reconstruct the mappings and connections between the blend, the neoclassical input space and the adaptive cycle input space. Finally, there is good reason for each element of the blend to be there, including relevant links to other mental spaces and relevant functions in running the blend. The decomposition of the natural language metaphors into their component primary metaphors and the recomposition of the primary metaphors into the blend is a methodology with which it is easy to check that each component primary metaphor has relevant links and relevant functions in running the blend (Table 1, column 4).

The Roller Coaster Blend is also cognitively appealing. I will highlight aspects of its cognitive appeal by running the blend in relation to an ongoing policy debate about degrowth. In the terminology of this paper, degrowth refers to the inevitable adjustment of the limitless cowboy economy to the absolute limits of the Earth's natural resources and the adaptation to a cyclical spaceship economy (Boulding 1996, Latouche 2007, Victor 2008, Jackson 2009). This exercise leads me to hypothesize better ways to formulate and communicate environmental policies that are cognitively appealing and link concerns over individual safety with those over socialecological survival (Antal and Hukkinen 2010).

First, the Roller Coaster Blend is a concrete way of illustrating that constant economic growth in a single dimension, which was termed potential or wealth above, is not possible: the roller coaster track has its absolute limits. At the same time, the image of a roller coaster on top of a hill is a cognitively appealing way of framing the message: Control is up. Second, the blend illustrates the meaning of Control is up. Growth and degrowth in wealth create opportunities for growth and degrowth in social-ecological connectedness and resilience, thus making simultaneous optimization for all three dimensions impossible (Gunderson and Holling 2002). Growth and recession, as perceived by the lonely rider struggling uphill on the slope of NCE, take on a richer meaning when placed in the roller coaster of the adaptive cycle. An increase or decrease in wealth is no longer a singularly good or bad thing. Increasing wealth also weakens vital socialecological networks or resilience against disruptions. As a result, the blend offers simple instructions for qualifying today's economic growth policy not as an end in itself but as preparation for long-term buildup of ecosystem services in the form of "green" investment (in the conservation stage) or for utilizing such investment to reorganize the economy (in the reorganization stage) (Figures 2 and 3). Put it another way, "a system [...] that at every given point of time fully utilizes its possibilities to the best advantage may yet in the long run be inferior to a system that does so at no given point of time, because the latter's failure to do so may be a condition for the level or speed of long-run performance" (Schumpeter 1976:73).

Third, the Roller Coaster Blend highlights the need to develop indicators for establishing evidence for different types of social-ecologically significant growth. Since optimizing simultaneously in all three dimensions of the adaptive cycle is impossible, it is clear that no single indicator, such as "green" GDP, can capture the dynamics of the SES. When one thing diminishes, it is cognitively appealing to see-with the help of appropriate indicators-that something else grows.

Fourth, the process of constructing the blend, particularly its first stage (Figure 3, Blend 1), hints at a cognitively appealing way of tackling systemic socio-economic inequalities (Jackson 2009). The roller coaster train was formed by linking the winner and the loser of the neoclassical race. Translated into concrete policies aiming to persuade the winners to link with the losers, this could mean social exclusion policies targeted at the wealthy, such as steeply progressive taxation, maximum wage limits, ineligibility for social services, and restricted access to publicly provided infrastructure. Some individuals whom global capitalism has made billionaires appear to have been persuaded even in the absence of such policies, as they voluntarily pledge to spread to charity at least half of their wealth (Blankinship 2010).

Last but not least, the Roller Coaster Blend points toward cognitively appealing ways of communicating the message about degrowth. From the cognitive perspective, the term is misleading. The cognitive appeal rests in the promise of 
continuous growth, albeit in the cyclically alternating dimensions of wealth, connections and resilience. This is crucially important, because it enables structuring future environmental policy messages in terms of the embodied primary metaphors that associate the subjective experiences of "more," "control" and "happy" with the sensorimotor experience of upward growth, and the subjective experiences of "less," "lack of control" and "unhappy" with the sensorimotor experience of downward dissipation (Lakoff and Johnson 1999). Thus, whichever stage in the growthdissipation cycle a SES happens to be in, the cognitively appealing communication would focus on what is growing rather than what is dissipating at that stage.

\section{CONCLUSION}

I have outlined the contours of a theoretical account of fit between human cognition and SESs by putting together insights from the study of the evolution of human cognition with Young's (2008) concept of institutional fit. My aim has been to show that the embodied cognition perspective opens up possibilities for facilitating social-ecological transitions toward sustainability through the conceptual integration of the cognitively attractive but ecologically unrealistic NCE, and the cognitively less attractive but ecologically more realistic ACT. The result is a conceptually integrated model, the Roller Coaster Blend, which expresses in metaphorical terms why competitive individuals are better off cooperating than competing with each other in the face of absolute resource limits. I have argued that the blend's potential for nudging evolution arises from its autopoietic characteristic: it can be both an account of the SES as an emergent structure that is capable of renewing itself, and a cognitive attractor of individuals whose recruitment reinforces the integrity of the SES.

Responses to this article can be read online at: http://www.ecologyandsociety.org/issues/responses. php/5241

\section{Acknowledgments:}

I thank Miklós Antal, Katharine N. Farrell, Juha Hiedanpää, Nina Honkela, two anonymous reviewers, and participants of the 2010 Albrecht Daniel Thaer Kolloquium in Berlin for valuable comments on earlier drafts of the manuscript. Financial support from the Academy of Finland Grants 217223 (Prodoe) and 140830 (RICCS), Maj and Tor Nessling Foundation Grant 2010112 (Regex) and European Commission 7th Framework Programme Project 214249 (Napanil) is gratefully acknowledged.

\section{LITERATURE CITED}

Antal, M., and J. Hukkinen. 2010. The art of the cognitive war to save the planet. Ecological Economics 69: 937-943. http:// dx.doi.org/10.1016/j.ecolecon.2010.01.002

Bateson, G. 1972. Steps to an Ecology of Mind. Ballantine Books, New York, NY, USA.

Bennett, J. W. 1996. Human Ecology as Human Behavior. Transaction Publishers, New Brunswick, NJ, USA.

Blankinship, D. G. 2010. Gates, Buffet lobby the rich for donation pledges. Bloomberg Business Week June 16. [online] URL: http://www.businessweek.com/ap/financialnews/D9GCG46G0. htm. (accessed 29 October 2010).

Boulding, K. E. 1955. Economic Analysis. Third Edition. Hamish Hamilton, London, UK.

Boulding, K. E. 1996. The economics of the coming spaceship Earth. Pages 357-367 in V. D. Lippit, editor. Radical Political Economy: Explorations in Alternative Economic Analysis. M. E. Sharp, New York, NY, USA.

Brock, W. A., K.-G. Mäler, and C. Perrings. 2002. Resilience and sustainability: the economic analysis of nonlinear dynamic systems. Pages 261-289 in L. H. Gunderson and C. S. Holling, editors. Panarchy: Understanding Transformations in Human and Natural Systems. Island Press, Washington, DC, USA.

Campbell, J. L. 2007. Why would corporations behave in socially responsible ways? An institutional theory of corporate social responsibility. Academy of Management Review 32(3): 946-967. http://dx.doi.org/10.5465/AMR.2007.25275684

Clark, A. 1997. Being There: Putting Brain, Body, and World Together Again. The MIT Press, London, UK.

Clark, A. 2011. Supersizing the Mind: Embodiment, Action, and Cognitive Extension. Oxford University Press, Oxford, UK. http://dx.doi.org/10.1007/s11098-010-9597-x

Daly, H. E. 1990. Sustainable development: from concept and theory to operational principles. Population and Development Review 16: 25-43. http://dx.doi.org/10.2307/2808061

D'Andrade, R. 1995. The Development of Cognitive Anthropology. Cambridge University Press, Cambridge, UK.

Dennett, D. C. 1991. Consciousness Explained. Little Brown, Boston, MA, UK.

Diamond, J. M. 2005. Collapse: How Societies Choose to Fail or Succeed. Viking Press, New York, NY, USA.

Ecological Economics. 2012. Homepage, http://www. elsevier.com/wps/find/journaldescription.cws home/503305/ description, accessed 11 June 2012. 
Ehrlich, P. R., and D. Kennedy. 2005. Millennium assessment of human behavior. Science 309: 562-563. http://dx.doi. org/10.1890/0012-9623-90.4.325

Fauconnier, G., and M. Turner. 1998. Conceptual integration networks. Cognitive Science 22(2): 133-187. http://dx.doi. org/10.1207/s 15516709 $\operatorname{cog} 2202 \_1$

Fauconnier, G., and M. Turner. 2002. The Way We Think: Conceptual Blending and the Mind's Hidden Complexities. Basic Books, New York, NY, USA.

Feldman, J. A. 2006. From Molecule to Metapor: A Neural Theory of Language. The MIT Press, Cambridge, MA, USA.

Fischer-Kowalski, M., and J. Rotmans. 2009. "Conceptualising, observing, and influencing social-ecological transitions. Ecology and Society 14(2): 3. [online] URL: http://www. ecologyandsociety.org/vol14/iss2/art3/.

Folke, C. and L. Gunderson. 2002. A kaleidoscope of change. Conservation Ecology 6(1): 19. [online] URL: http://www. consecol.org/vol6/iss1/art19/.

Gentner, D. 1983. Structure-Mapping: A Theoretical Frameworkfor Analogy. Cognitive Science 7: 155-170. http:// dx.doi.org/10.1207/s15516709 $\operatorname{cog} 07023$

Gentner, D., K. J. Holyoak, and B. N. Kokinov, editors. 2001. The Analogical Mind: Perspectives from Cognitive Science. The MIT Press, Cambridge, MA, USA.

Gould, S. J. 2000. Deconstructing the "Science Wars" by reconstructing an old mold. Science 287: 253-261. http://dx. doi.org/10.1126/science.287.5451.253

Gunderson, L. H., and C. S. Holling, editors. 2002. Panarchy: Understanding Transformations in Human and Natural Systems. Island Press, Washington, DC, USA.

Hofstadter, D. R. 1979. Gödel, Escher, Bach: An Eternal Golden Braid. Vintage, New York, NY, USA.

Holling, C. S. 1973. Resilience and stability of ecological systems. Annual Review of Ecology and Systematics 4: 1-23. http://dx.doi.org/10.1146/annurev.es.04.110173.000245

Holling, C. S., editor. 1978. Adaptive environmental assessment and management. John Wiley \& Sons, London, UK.

Holling, C. S. 2004. From complex regions to complex worlds. Ecology and Society 9(1): 11. [online] URL: http://www. ecologyandsociety.org/vol9/iss1/art11.

Holling, C. S., and L. H. Gunderson. 2002. Resilience and adaptive cycles. Pages 25-62 in L. H. Gunderson and C. S. Holling, editors. Panarchy: Understanding Transformations in Human and Natural Systems. Island Press, Washington, DC, USA.
Hutchins, E. 1995. Cognition in the Wild. MIT Press, Cambridge, MA, USA.

Jackson, T. 2009. Prosperity Without Growth: Economics for a Finite Planet. Earthscan, London, UK.

Jantsch, E. 1980. The Self-Organizing Universe: Scientific and Human Implications of the Emerging Paradigm of Evolution. Pergamon Press, Oxford, UK.

Lakoff, G., and M. Johnson. 1980. Metaphors We Live By. The University of Chicago Press, Chicago, IL, USA.

Lakoff, G., and M. Johnson. 1999. Philosophy in the Flesh: The Embodied Mind and Its Challenge to Western Thought. Basic Books, New York, NY, USA.

Latouche, S. 2007. Petit traité de la décroissance sereine. Mille et Une Nuits, Paris, France.

Lukes, S. 2005. Power: A Radical View. Second Edition. Palgrave Macmillan, New York, NY, USA.

Maturana, H. R. 2002. Autopoiesis, Structural Coupling and Cognition: A history of these and other notions in the biology of cognition. Cybernetics \& Human Knowing 9(3-4): 5-34.

Maturana, H. R., and F. J. Varela. 1980. Autopoiesis and Cognition: The Realization of the Living. D. Reidel, Dordrecht, Boston, London, UK.

McNeill, J. R. 2000. Something New Under the Sun: An Environmental History of the Twentieth-Century World. Norton, New York, NY, USA.

Norgaard, R. B. 1994. Development Betrayed: The End of Progress and a Coevolutionary Revisioning of the Future. Routledge, London and New York, NY, USA.

North, D. C. 1981. Structure and Change in Economic History. W. W. Norton, New York, NY, USA.

North, D. C. 2005. Understanding the Process of Economic Change. Princeton University Press, Princeton, NJ, USA.

Ostrom, E. 2007. A diagnostic approach for going beyond panaceas. Proceedings of the National Academy of Sciences 104(39): 15181-15187. http://dx.doi.org/10.1073/pnas.0702288104

Ostrom, E. 2009. A general framework for analyzing sustainability of social-ecological systems. Science 325: 419-422. http://dx.doi.org/10.1126/science.1172133

Ostrom, E., M. A. Janssen, and J. M. Anderies. 2007. Going beyond panaceas. Proceedings of the National Academy of Sciences 104(39): 15176-15178. http://dx.doi.org/10.1073/ pnas.0701886104

Peterson, W. C. 1973. Elements of Economics. W. W. Norton, New York, NY, USA. 
Petrella, R. 2009. Deux obstacles sur le chemin de Copenhague. Le Monde Diplomatique, Décembre, pp. 10-11. http://www.monde-diplomatique.fr/2009/12/PETRELLA/18574

Polski, M. M. 2009a. Essays on Wired for Survival: Integrating neuroscience and institutional analysis and development. Paper prepared for the Workshop on the Workshop 4, Indiana University Bloomington, June 3-6 (http:// mason.gmu.edu/ mpolski/documents/PolskiNeuroIAD2009.pdf, accessed 31 October 2010).

Polski, M. M. 2009b. Wired for Survival. FT Press, Upper Saddle River, NJ, USA.

Redman, C. L. 1999. Human Impact on Ancient Environments. University of Arizona Press, Tucson, AZ, USA.

Rockström, J., W. Steffen, K. Noone, A. Persson, F. S. Chapin, III, E. F. Lambin, T. M. Lenton, M. Scheffer, C. Folke, H. J. Schellnhuber, B. Nykvist, C. A. de Wit, T. Hughes, S. van der Leeuw, H. Rodhe, S. Sörlin, P. K. Snyder, R. Costanza, U. Svedin, M. Falkenmark, L. Karlberg, R. W. Corell, V. J. Fabry, J. Hansen, B. Walker, D. Liverman, K. Richardson, P. Crutzen, and J. A. Foley. 2009. A safe operating space for humanity. Nature 461: 472-475. http://dx.doi.org/10.1038/461472a

Rosch, E. H. 1973. Natural categories. Cognitive Psychology 4(3): 328-350. $\quad$ http://dx.doi.org/10.1016/0010-0285(73) $\underline{90017-0}$

Roller Coaster DataBase. 2010. http://www.rcdb.com/, last modified 24 September 2010, accessed 29 September 2010.

Sawyer, R. K. 2005. Social Emergence: Societies as Complex Systems. Cambridge University Press, New York, NY, USA.

Shapiro L. 2011. Embodied Cognition. Routledge, London and New York.

Schumpeter, J. A. 1976 [1943]. Capitalism, Socialism and Democracy. Routledge, London and New York.

Scott, W. R. 1987. Organizations: Rational, Natural, and Open Systems, 2nd Edition. Prentice-Hall, Englewood Cliffs, NJ, USA.

Slingerland, E. 2008. What Science Offers the Humanities. Cambridge University Press, Cambridge, MA, USA.

Smil, V. 1993. Global Ecology: Environmental Change and Social Flexibility. Routledge, London, UK.

Smith, A. 1937. The Wealth of Nations. E. Cannan edition. The Modern Library, New York, NY, USA. http://dx.doi. org/10.1002/9781118011690.ch9

Thaler, R. H., and C. R. Sunstein 2008. Nudge: Improving Decisions About Health, Wealth, and Happiness. Yale University Press, New Haven \& London, UK.
Tomasello, M. 1999. The Cultural Origins of Human Cognition. Harvard University Press, Cambridge, MA, USA.

Turner, M., and G. Fauconnier. 1999. A mechanism of creativity. Poetics Today 20(3): 397-418.

Varela, F. G., H. R. Maturana, and R. Uribe. 1974. Autopoiesis: The organization of living systems, its characterization and model. Biosystems 5(4): 187-196. http:// dx.doi.org/10.1016/0303-2647(74)90031-8

Varela, F. J., E. Thompson, and E. Rosch. 1991. The Embodied Mind: Cognitive Science and Human Experience. The MIT Press, Cambridge, MA, USA.

Victor, P. 2008. Managing Without Growth: Slower By Design, Not Disaster. Edward Elgar, Northampton, MA, USA.

Westley, F. 2002. The devil in the dynamics: Adaptive management on the front lines. Pages 333-360 in L. H. Gunderson and C. S. Holling, editors. Panarchy: Understanding Transformations in Human and Natural Systems. Island Press, Washington, DC, USA.

Westley, F., S. R. Carpenter, W. A. Brock, C. S. Holling, and L. H. Gunderson. 2002. Why systems of people and nature are not just social and ecological systems. Pages 103-119 in L. H. Gunderson and C. S. Holling, editors. Panarchy: Understanding Transformations in Human and Natural Systems. Island Press, Washington, DC, USA.

Young, O. R. 2008. The Architecture of Global Environmental Governance: Bringing Science to Bear on Policy. Global Environmental Politics 8(1): 14-32. http://dx.doi.org/10.1162/ glep.2008.8.1.14 


\section{APPENDIX 1. The Riddle of the Buddhist Monk}

A well-known example of a conceptual blend is the inferential solution to the riddle of the Buddhist monk, analyzed by Fauconnier and Turner (1998:136-141). The monk begins walking up a mountain at dawn, reaches the top at sunset and meditates there for several days. One dawn he begins to walk back to the foot of the mountain and reaches it at sunset. Making no assumptions about his starting, stopping or pace during the trips, our task is to prove that there is a place on the path which he occupies at the same time of day on the two journeys.

The inferential solution to the riddle is to imagine the monk walking both up and down the path on the same day. There must be a place where he "meets himself" on the path and that place is the one he would occupy at the same time on the two journeys. Fauconnier and Turner (1998) analyze the inferential solution by breaking up the riddle and its solution into mental spaces (a more specific term for the domains of knowledge to which I refer in Section 2 of the main text when describing metaphorical mapping). Mental spaces are "small conceptual packets constructed as we think and talk, for purposes of local understanding and action" (Fauconnier and Turner 1998:137). There are three types of mental space: input space, blended space and generic space. In the riddle, for example, there are two input spaces, in which $d_{1}$ is the day of the upward journey, $d_{2}$ the day of the downward journey, $a_{1}$ the monk going up and $a_{2}$ the monk going down (Figure A1.1). The blended space consists of a single day d' which is the fusion of the two days of travel $\mathrm{d}_{1}$ and $\mathrm{d}_{2}$, and monks $a_{1}$ ' and $a_{2}$ ' which are the counterparts of $a_{1}$ and $a_{2}$ at time $t$ ' (Fauconnier and Turner 2002:41-42). Generic space (not shown in Figure A1.1) contains what the input spaces have in common.

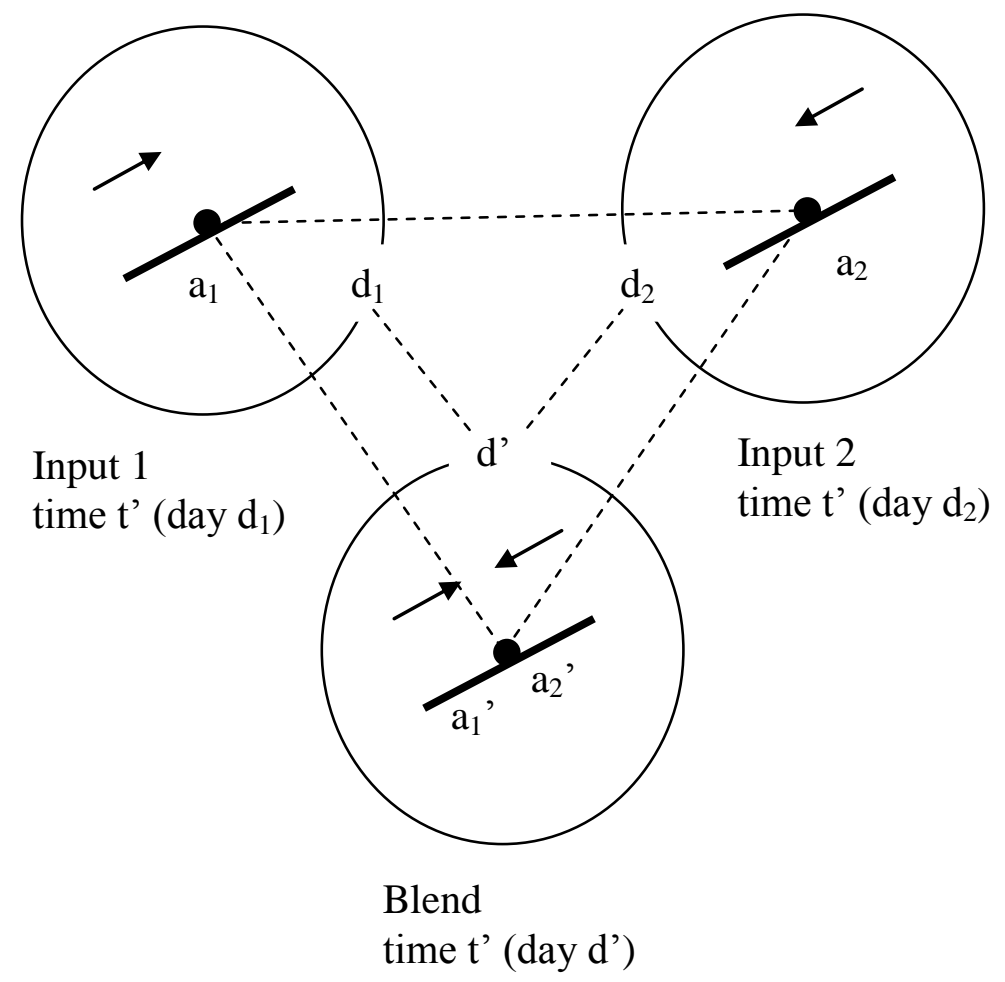

Figure A1.1. Conceptual blending as a solution to the Buddhist monk riddle (adapted from Fauconnier and Turner 1998:141, Fig. 5). 
The monk riddle illustrates the three operations of blending that are explained in the main text. The riddle composes the two travelers making two journeys; it completes the composed structure by recruiting the well-known scenario of two people encountering each other on a path; and it can be elaborated by running an imaginative mental simulation according to the principles of the blend. The simulation example Fauconnier and Turner use is that the imaginary two monks would meet each other and begin a discussion on the concept of identity (Fauconnier and Turner 1998). 


\section{APPENDIX 2. Decomposition of event structure metaphors and conceptual blending of primary metaphors}

\section{Decomposition of event structure metaphors}

System is a physical structure. See Analysis section in the main text.

States are locations, Changes are movements, Causes are forces. In neoclassical economics, the state of the economic system and its individual actors can in embodied terms be described as a lonely rider on the uphill slope striving to maximize his money and power. The more money and power he has been able to accumulate, the higher up on the slope he is. The uphill movement continues forever and any downhill slide is only temporary. As a reflection of the role of ecosystem services in the economy, the slope does not erode from traveling on it (Table 1, column 2). In contrast, the dynamics of the adaptive cycle of a socio-ecological system can be described as a roller coaster track. System state is determined by location along the roller coaster track, following the cyclic growth and dissipation of potential, connectedness and resilience (Table 1, column 3 ).

Actions are self-propelled movements, Purposes are destinations, Means are paths, Expected progress is travel schedule. In the neoclassical economy, lonely riders are the actors whose purpose is to stick to the uphill path, to stay ahead of the others in the competition, to remain inside the vehicle and to maintain the vehicle in good shape (Table 1, column 2). In the adaptive cycle, the society is the actor, moving at variable speed along the roller coaster track. The purpose is to maintain the adaptive capacity of the system by building and repairing the track. Progress is not maximal but optimal speed along the track. Interestingly, growth and dissipation are each other's means: growth requires dissipative turns on the track and vice versa (Table 1, column 3).

Difficulties are impediments to motion, External events are large moving objects, Long-term purposeful activities are journeys. For the lonely rider in a neoclassical economy, the purposeful life is spent speeding uphill ahead of others. The occasional recession is like a landslide causing an uncontrolled slide downhill. Regulation is having to carry a heavy burden or encountering rough terrain (Table 1, column 2). In contrast, the purpose of a socio-ecological system is a pleasant roller coaster ride. Systemic breakdown is like a collapsing roller coaster track. Regulation becomes a difficulty for the system if it prevents experimentation with safe roller coaster track design (Table 1, column 3).

\section{Conceptual blending of primary metaphors}

System is a physical structure. See Analysis section in the main text.

States are locations, Changes are movements, Causes are forces. In the conceptual blend, the adaptive roller coaster riders are those who remain linked together on the roller coaster track. Sometimes, but not always, they may even have wealth like their counterparts in the neoclassical input space. This is because wealth, which is the equivalent of potential in the adaptive cycle, is contingent upon growth and dissipation in the two other dimensions of the adaptive cycle, namely, connectedness and resilience. Wealth is high or increasing in two types of situation, namely, when resilience diminishes in the conservation $(\mathrm{K})$ stage of the adaptive cycle or when connectedness diminishes in the reorganization $(\alpha)$ stage. Wealth is low or diminishing when resilience is low in 
the release $(\Omega)$ stage of the adaptive cycle or when both resilience and connectedness increase in the exploitation (r) stage (Figures 2 and 3). The management instruction that emerges from these tradeoffs for the roller coaster riders is not to maximize wealth but rather coordinate it with connections and resilience to maintain optimal movement along the roller coaster track. Obviously, a smooth ride presumes good maintenance of the roller coaster track (Table 1, column 4).

Actions are self-propelled movements, Purposes are destinations, Means are paths, Expected progress is travel schedule. The riders' collective movement in a roller coaster along the cycleshaped track has the overall purpose of remaining adaptive during the ride. Adaptation in turn is made of several attributes, including riders who maintain the roller coaster and the track, stay inside the vehicle during the ride, keep the vehicle on the track and experiment with the safe limits of roller coaster speed. Some riders may even change roller coasters at the bottom station, reflecting the socio-ecological system's ability to both influence the dynamics of lower level systems and be influenced by higher level systems (Holling 2004). In striving to achieve these purposes, the riders must pay attention to tradeoffs inherent in the ride dynamics: to achieve growth in one desired dimension requires an acceptance of reductions in other dimensions. Advancement of one's personal career is judged in terms of its contribution to achieving an optimal speed during the collective ride (Table 1, column 4).

Difficulties are impediments to motion, External events are large moving objects, Long-term purposeful activities are journeys. Difficulties and opportunities are also in a tradeoff. Statements of difficulties in the blend are themselves blends between primary metaphors expressing difficulties in neoclassical economics and primary metaphors expressing means in adaptive cycle theory. Recession, for example, is gaining speed in a downhill to be able to climb up the next uphill slope on the roller coaster track; and losing competition is waiting for the right moment to climb up. If regulation becomes a difficulty, it is because it prevents experimentation with safe roller coaster design and operation. The worst that can happen is a complete breakdown of the socio-ecological system, which is like a collapsing roller coaster. The best that can happen is a pleasant roller coaster ride with fellow riders (Table 1, column 4 and Figure 3). 